TERRA. Revista de Desarrollo Local e-ISSN: 2386-9968

Número 6 (2020), 323-330

DOI 10.7203/terra.6.17767

IIDL - Instituto Interuniversitario de Desarrollo Local

\title{
La interpretación del paisaje como herramienta para la dinamización local: entre olivos milenarios y alcornoques en las comarcas de Castelló
}

\begin{abstract}
Chema Rabasa Edo
Ldo. en Ciencias Ambientales y Máster en Restauración Ecológica del Medio Natural. Dtor. Área Senderismo Interpretativo ITINERANTUR (Benicàssim, Castellón, España)

info@itinerantur.com

\section{Inés Vivas Gimeno}

Diplomada en Magisterio, Graduada en Geografía y Medio Ambiente y Máster en Biodiversidad. Coordinadora de Proyectos Pedagógicos ITINERANTUR (Benicàssim, Castellón, España)

inesvivasg@gmail.com
\end{abstract}

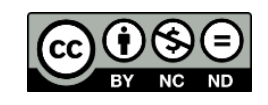

Esta obra se distribuye con la licencia Creative Commons

Reconocimiento-NoComercial-SinObraDerivada 4.0 Internacional 


\section{SECCIÓN EXPERIENCIAS Y BUENAS PRÁCTICAS}

\section{La interpretación del paisaje como herramienta para la dinamización local: entre olivos milenarios y alcornoques en las comarcas de Castelló}

Resumen: La interpretación del Paisaje se presenta como una herramienta clave para la dinamización local de gran interés, y, con ello, como una aportación más para la conservación del patrimonio y la lucha contra la despoblación, uno de los mayores problemas que afligen a los espacios rurales españoles, pero también valencianos. Por varios motivos: primero, los destinos de interior y el turismo de naturaleza y cultural ganan peso respecto al, todavía, imperante turismo de sol y playa; segundo, el contexto de las nuevas demandas por un Turismo Responsable, como la reciente creación del manifiesto Turismo Reset; y, tercero, atendiendo a la necesidad de buscar propuestas tangibles para movilizar los municipios de interior y luchar contra su abandono.

Palabras clave: Planificación, desarrollo local, turismo, gobernanza, participación.

Recibido: 22 de junio de 2020

Devuelto para revisión: -

Aceptado: 22 de junio de 2020

\section{Referencia / Citation:}

Rabasa, C., y Vivas, I. (2020). La interpretación del paisaje como herramienta para la dinamización local: entre olivos milenarios y alcornoques en las comarcas de Castelló. TERRA. Revista de Desarrollo Local, (6), 323-330. DOI 10.7203/terra.6.17767 


\section{EL PAISAJE}

Al tratar de definir la palabra "paisaje", se toma conciencia de la complejidad de su significado, pues este se ha abordado desde diversas disciplinas y con distintas perspectivas, dando lugar a gran cantidad de interpretaciones desde el siglo XIX. Según el Convenio Europeo del Paisaje (2000) este se entiende como cualquier parte del territorio tal como la percibe la población, cuyo carácter es el resultado de la acción y la interacción de factores naturales o humanos. Un paisaje que, en un caso como el nuestro, el Mediterráneo, posee una estrecha relación con el ser humano, de manera que es casi imposible encontrar lugares en los que no se hayan dado interacciones entre el medio físico y natural y los seres humanos que lo habitan. Es por eso que hablamos de paisajes culturales. Como decimos en Itinerantur, en el Mediterráneo naturaleza y cultura van de la mano; no se entiende una sin la otra. Así, cuando caminamos por nuestras comarcas valencianas, cuando salimos de los núcleos habitados y levantamos la mirada en algún punto que elegimos como mirador, lo que en la mayoría de casos estamos viendo es un bello y complejo paisaje cultural: secanos, frutales, regadíos, masías, huertas, balsas, retales de bosque de ribera, poblados y despoblados, pinares, matorrales, campos abandonados... Incluso si pensamos en los Parques Naturales de nuestro territorio, la relación con el ser humano ha sido clave para su configuración actual, constituyendo un verdadero mosaico compuesto de diferentes piezas, un "puzle" territorial.

\section{Figura 1. Interpretación del Paisaje}

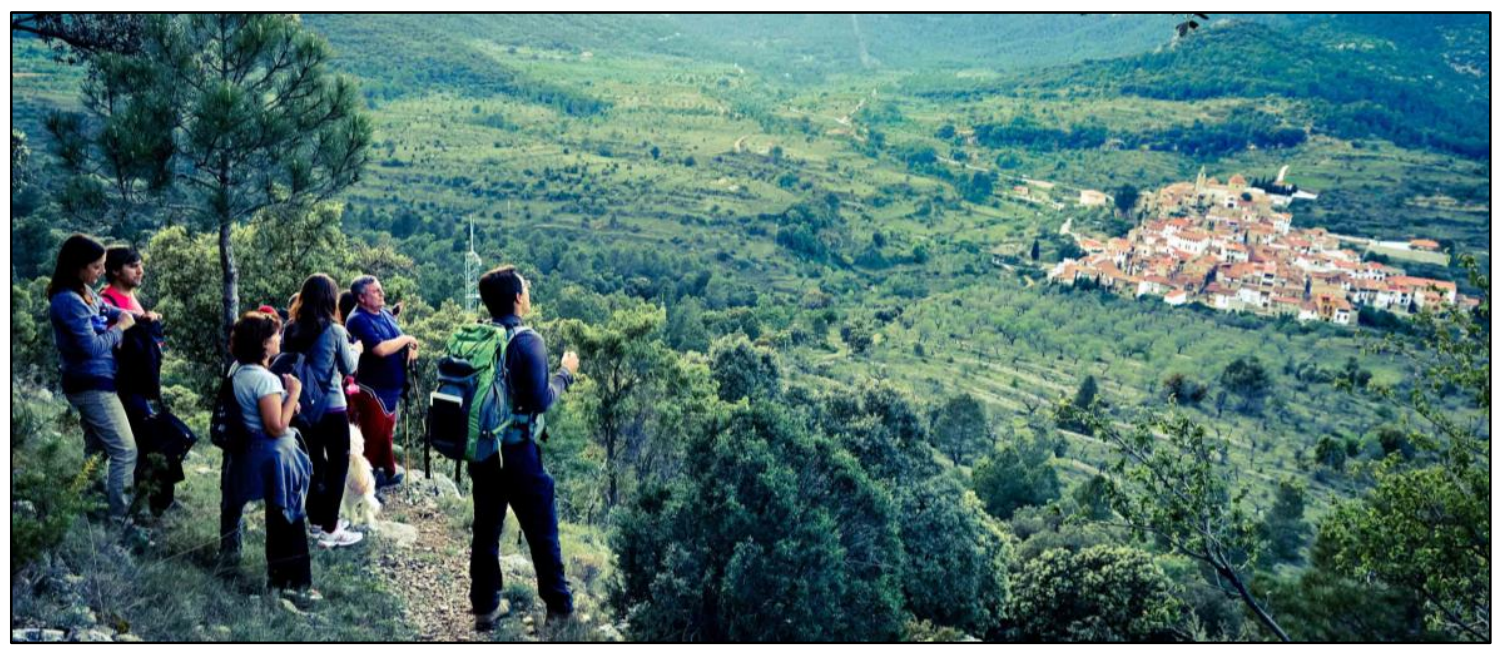

Fuente: Itinerantur.

\section{UNA PUESTA EN VALOR RESPONSABLE}

La pregunta que surge a continuación, pensando en la situación demográfica de muchos municipios es: "¿cómo mantener vivo un paisaje cultural antiguo, biodiverso, valioso, si hoy nadie o casi nadie vive en él?". Nosotros pensamos que, bien y participativamente planificada, la actividad turística es una respuesta factible, pudiendo ser esta la vía para compatibilizar desarrollo económico equilibrado con la conservación y mejora de nuestro medio natural-cultural. Y es este el punto clave a partir del cual se desarrolla la propuesta de Itinerantur: muchos de nuestros paisajes cuentan con activos patrimoniales y, por tanto, 
son susceptibles de ser aprovechados responsablemente por una comunidad local para generar un potencial atractivo turístico, que ayude a dinamizar la economía del municipio o de la comarca.

En este contexto, cobra interés el concepto de Turismo Responsable que, teniendo en cuenta los principios básicos establecidos por Harold Goodwin (2002) ${ }^{1}$, se puede considerar como un conjunto de iniciativas que apuestan por el turismo local, sosegado, de naturaleza y cultura, que verdaderamente dinamizan a la población del lugar que se visita para que sea esta la que decida cómo quiere que el forastero conozca su tierra. Lleva implícito, además, un compromiso con el desarrollo equilibrado de las sociedades locales para que todos podamos disfrutar siempre de los paisajes en buen estado de conservación que aún nos quedan.

\title{
3. LA INTERPRETACIÓN DEL PAISAJE COMO HERRAMIENTA PARA LA DINAMIZACIÓN LOCAL
}

\begin{abstract}
"La interpretación consiste en ayudar a enamorar. El patrimonio natural y cultural necesita ser querido. No debería molestar a los intérpretes ser tildados de alcahuetes, de amables celestinas ocupadas en descubrir al visitante los más secretos atractivos, las más disimuladas virtudes del espacio -parque natural, conjunto histórico, ecomuseo, etc.-que interpretan” (Miguel Delibes de Castro).
\end{abstract}

Debemos tener presente que la interpretación puede realizarse a través de un guía, pero también, mediante el diseño y creación de itinerarios autoguiados, a través de paneles interpretativos sobre el tema en cuestión. Para llegar a ello, se ponen en marcha diversos procedimientos que, ya desde el momento inicial, pueden contribuir a la dinamización local o regional, como por ejemplo al recorrer el territorio para identificar los distintos recursos territoriales o atender a las diversas tipologías paisajísticas presentes.

Pero no nos quedemos ahí. La clave para que la Interpretación del Paisaje sirva como herramienta de dinamización local es contar, justamente, con la población local a través de procesos de participación ciudadana para tomar decisiones, aportar ideas y compartir conocimientos. Es más, acercar la Interpretación del Paisaje a la población local para que conozca, sienta como propio, ame y quiera conservar su patrimonio, formándola incluso para que sea esta misma población la que después interprete su paisaje frente a los visitantes de la localidad, es indispensable para la puesta en valor del patrimonio de forma sostenible y para su correcta gestión en el marco de una actividad turística participativa y responsable.

En nuestra experiencia profesional, tenemos claro que es necesario establecer sinergias con la población local para desarrollar una actividad turística responsable y de calidad, ya sea en las fases de preparación y recopilación de la información como, posteriormente, a la hora de diseñar el producto turístico final: desde los agricultores y productores locales a los empresarios de restauración y alojamientos, pasando por empresas de turismo activo, guías, etc. Si además se establece una relación de colaboración entre dichos actores y la administración pública local, las sinergias se multiplican.

\footnotetext{
${ }^{1}$ En la primera Conferencia Internacional sobre Turismo Responsable en Ciudad del Cabo.
} 


\section{EJEMPLOS DE PRODUCTOS VINCULADOS A LA INTERPRETACIÓN DEL PAISAJE Y DINAMIZADORES DE LA ECONOMÍA LOCAL}

\subsection{Los olivos milenarios del Maestrat}

Un ejemplo de éxito en este tipo de productos turísticos, y que ya llevamos años desarrollando, es el que realizamos alrededor de las localidades de Canet lo Roig y Traiguera (Baix Maestrat, Castelló). Es en esta histórica y norteña comarca valenciana donde podemos encontrar la mayor cantidad de olivos monumentales catalogada hasta el momento en todo el mundo. Hay más de cinco mil árboles de este tipo hasta la fecha, todos ellos de la variedad local Farga, y en incontables casos, superan los mil o mil quinientos años de edad. Todos ellos vivos y produciendo zumo de oliva año tras año desde hace siglos.

Durante décadas, los conocidos como 'Olivos Milenarios' fueron a cientos arrancados de su parcela y vendidos a propietarios públicos y privados para decorar jardines, rotondas, patios, etc., en toda Europa. Hay que tener en cuenta que son árboles menos productivos que sus homólogos jóvenes, cada uno ocupa una gran superficie, y llegaron a alcanzar precios muy elevados, de hasta cinco cifras en euros, con lo cual muchos propietarios sucumbieron a su venta y al consiguiente espolio patrimonial. Se ha llegado, incluso, a filmar una película con este trasfondo: El Olivo (Icíar Bollaín, 2016), nominada e, incluso, ganadora de algunos premios Goya.

Gracias a la presión social, estos monumentos vivientes están protegidos por la Ley 4/2006, de 19 de mayo, de Patrimonio Arbóreo Monumental de la Comunitat Valenciana. En términos generales, ya no se pueden arrancar, vender ni transportar olivos monumentales dentro del territorio valenciano. Sin embargo, siguen siendo propiedad privada y no hay, de momento, incentivos económicos para que sus dueños los cuiden y los mantengan esplendorosos y en producción, más allá del alto precio que se cobra por el Aceite de Oliva Virgen Extra (AOVE) de olivos milenarios. Por ello, muchos siguen estando en peligro de abandono e imparable decaimiento y muerte.

No obstante, sabemos que el 'Mar de Olivos Milenarios del Baix Maestrat' es, patrimonial y paisajísticamente hablando, suficientemente potente como para generar una demanda turística realmente sostenible y que funcione como motor social e incentivo económico, para que dicho paisaje siga activo y sea conservado por quienes habitan en él. De hecho, llevamos poniéndolo en práctica desde el año 2014.

Tanto por cuenta propia para grupos particulares como con el patrocinio del municipio de Canet lo Roig, programamos anualmente una serie de experiencias de inmersión turística. En ellas recorremos, mediante distintas actividades de senderismo interpretativo pensadas para diversas edades y tipos de público, el mosaico paisajístico local, en el que sobresalen cientos de olivos milenarios: se explica su origen, sus características ecológicas como planta mediterránea, la Historia y sus historias, mitos y curiosidades, problemas e impactos que sufren. Se pone en contacto íntimo al visitante con el patrimonio vivo que se interpreta.

Además, se cuenta con los productores locales de AOVE proveniente de los olivos milenarios: ellos se encargan de guiar catas de aceite y explicar el valor de este alimento al que denominamos 'oro líquido'. Tras esta experiencia sensorial (en la que se ha puesto en valor el paisaje cultural en sentido amplio), los asistentes acuden a un restaurante local a comer y adquirir el aceite local. 
La experiencia de agroturismo se suele complementar tanto con la visita a una histórica bodega de vinos local (L'Estanquer, por ejemplo) y la cata de sus mejores caldos, como con una experiencia puramente cultural: la visita al Real Santuario de la Font de la Salut, en Traiguera, monumento único a escala estatal, interpretado por un guía experto local. $\mathrm{Si}$ el curioso visitante lo desea, se puede comer directamente en el santuario, en un restaurante de altísima calidad y producto $100 \%$ local y de temporada, situado en la antigua 'Casa dels Capellans'.

En resumen, se ofrecen muchas y variadas motivaciones económicas para que la población de la comarca siga queriendo mantener el paisaje que propicia dichas motivaciones. No olvidemos que un gran porcentaje de las familias de la zona poseen, entre su patrimonio heredado, olivos milenarios, y todos pueden ser, de una u otra manera, beneficiados por su conservación activa.

Figura 2. Degustación de productos locales

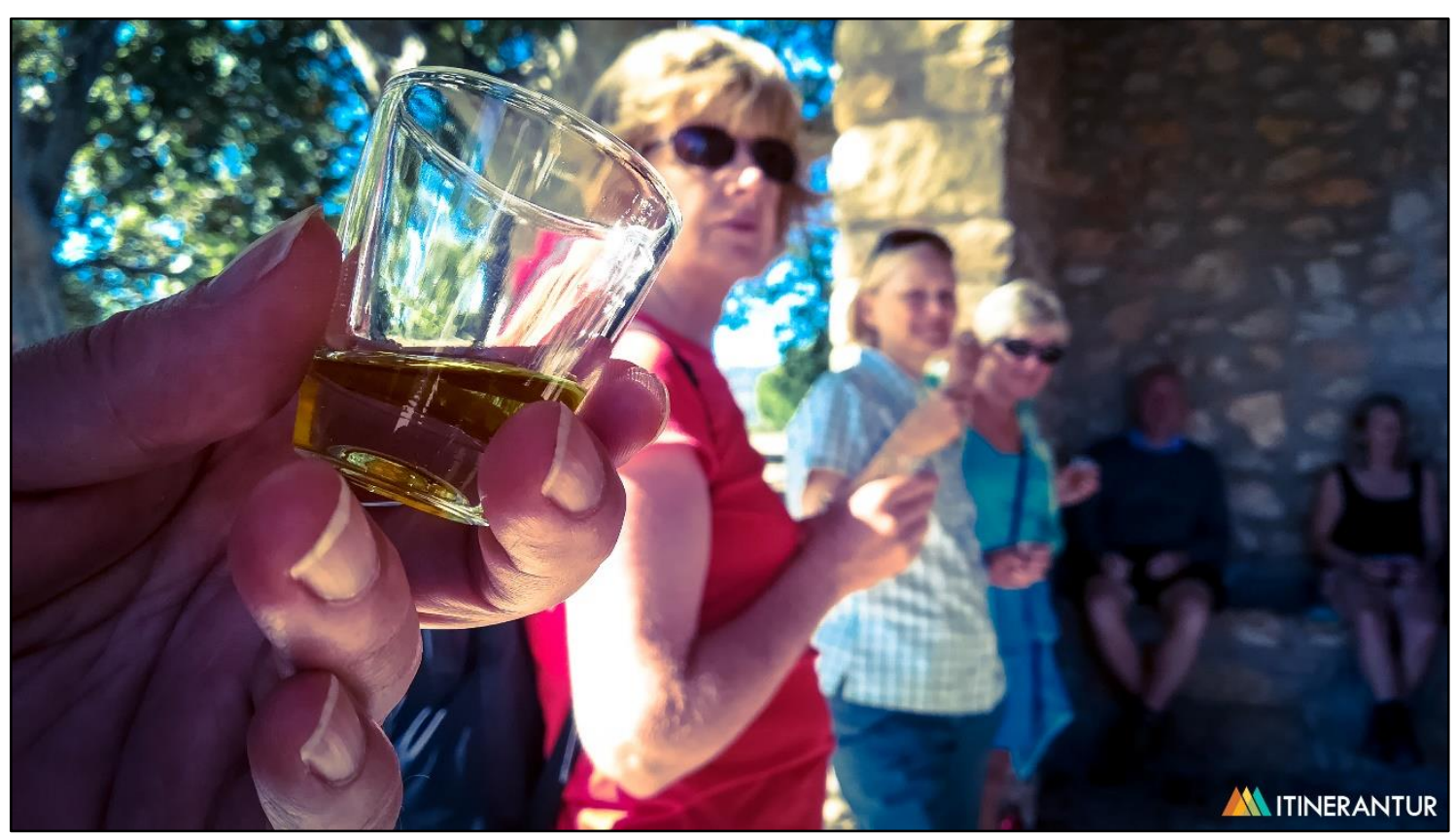

Fuente: Itinerantur.

\subsection{Almedíjar: sorpresas gastronómicas en la selva mediterránea}

Otro ejemplo similar lo encontramos en Almedíjar, un municipio enclavado en la cara SW del Parque Natural de la Sierra de Espadán, que en Itinerantur conocemos como la 'Selva Mediterránea' debido a las especiales condiciones ecológicas de los alcornocales montanos allí magníficamente representados, los cuales no dejan de ser un ecosistema influido por el ser humano desde tiempos inmemoriales.

El cuidado y el cultivo de los alcornoques para la producción de corcho para tapones, una actividad arraigada en Espadán desde la Edad Media, pero intensa y especialmente desde el siglo XIX, ha dado lugar a modos de vida propios de la zona, y a un paisaje selvático como no se puede encontrar en muchos cientos de kilómetros alrededor. No obstante, el oficio de sacador de corcho está en franco peligro de desaparición debido a múltiples factores socioeconómicos. 
A partir de los llamados "paisajes del corcho", se ha diseñado un producto turístico de rutas de Interpretación del Paisaje, con especial atención al barranco de Almanzor, llamado así por el antiguo líder de las Revueltas Moriscas de Espadán, del siglo XVI; a las historias y leyendas alrededor de aquel conflicto bélico; a los árboles monumentales allí presentes, y al bosque alrededor de la masía Mosquera, antiguo centro de producción local de corcho, posiblemente uno de los alcornocales más densos de la Península Ibérica.

Además, se visitan empresas locales y se consumen sus productos, como la quesería artesana "Los Corrales", especializada en quesos de autor elaborados de forma tradicional (con cuajo vegetal) e, incluso, con leche del último rebaño lechero de la oveja autóctona valenciana Guirra, rescatado por la quesería. También visitamos la bodega cooperativa "Alcovi", que elabora vinos de pequeñas viñas enclavadas entre pinares y alcornoques del propio arque natural, y degustamos sus vinos maridados con los quesos artesanales.

Por si fuera poco, durante las semanas que dura la saca del corcho (finales de junio y principios de julio, normalmente) centramos la experiencia en conocer y ver in situ algo único en todo el territorio valenciano: el proceso de extracción del corcho como se ha hecho y se hace actualmente, a la manera tradicional. Es, de hecho, Manolo Fuster, uno de los cooperativistas de la bodega local, quien realiza la extracción del corcho para los asistentes, ya que es uno de los oficios que practica cada año (Figura 3).

Figura 3. Implicación de los actores locales

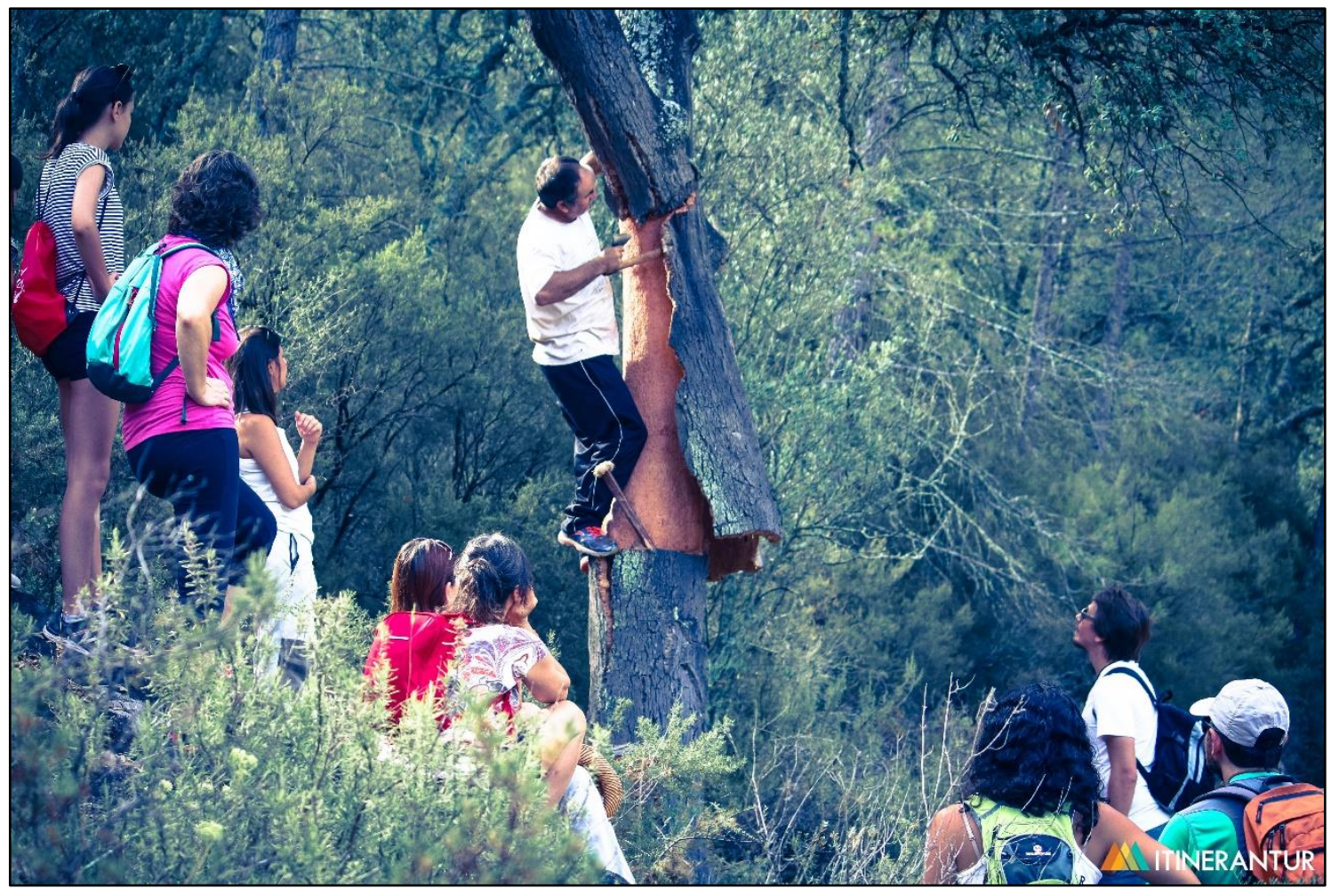

Fuente: Itinerantur.

En Almedíjar, tanto desde la administración como desde el colectivo "Almedíjar Vive" formado por algunos vecinos y asociaciones del pueblo, y junto a otras empresas especializadas en el diseño de contenidos interpretativos, se están llevando a cabo iniciativas muy interesantes para poner en valor el patrimonio natural y cultural, fomentar 
un turismo responsable basado en la conservación del medio ambiente y del patrimonio, e integrando a diversos sectores económicos en el proceso.

\section{REFLEXIONES FINALES}

Hemos visto a partir de dos ejemplos tangibles y que se están ejecutando actualmente, cómo la Interpretación del Paisaje puede suponer un eje vertebrador dentro de la creación de productos turísticos responsables que sirvan para dinamizar el territorio. Para ello, es imprescindible implicar a la propia población en la toma de decisiones y el diseño de las experiencias, poner en valor los distintos recursos (naturales, culturales, artísticos, y gastronómicos) del municipio y su paisaje, y trabajar con personal cualificado, comprometido e implicado en la conservación del mismo. 